\title{
Comparative Radical Scavenging and Antidiabetic Activities of Methanolic Extract and Fractions from Achillea ligustica ALL.
}

\author{
Filomena Conforti, ${ }^{*}$ Monica Rosa Loizzo, Giancarlo Antonio Statti, and Francesco Menichini \\ Department of Pharmaceutical Sciences, University of Calabria; I-87036 Rende (CS), Italy. \\ Received February 21, 2005; accepted May 10, 2005
}

\begin{abstract}
The yield of methanolic extract and total phenol and non polar content of flowered parts from Achillea ligustica ALL. are reported. GC-MS analysis of the non polar fraction showed that the triterpene moretenol was the major constituent $(17.228 \%)$ followed by stigmast-6-en-3 $\beta$-ol, veridiflorol and $\beta$-amyrin $(7.524 \%, 5.078 \%$ $4.470 \%$, respectively). The antioxidant activities of the methanolic extract and its fractions from $A$. ligustica were carried out using two different in vitro assays, 2,2-diphenyl-1-picrylhydrazyl (DPPH) test and lipid peroxidation of liposomes assay. Methanolic extract showed higher radical scavenging activity on DPPH (IC ${ }_{50}$ of $\left.50 \mu \mathrm{g} / \mathrm{ml}\right)$. This activity is probably due to the phenolic fraction which shown an $\mathrm{IC}_{50}$ value of $22 \mu \mathrm{g} / \mathrm{ml}$. A different result was obtained from the methanolic extract on the lipid peroxidation of liposomes $\left(\mathrm{IC}_{50} \mathrm{of} 416 \mu \mathrm{g} / \mathrm{ml}\right)$. The $\alpha$-amylase inhibition assay was applied to evaluate antidiabetic activity. The methanolic extract showed weak activity $(28.18 \%$ at $1 \mathrm{mg} / \mathrm{ml})$ while the $n$-hexane fraction showed $74.96 \%$ inhibition at $250 \mu \mathrm{g} / \mathrm{ml}$.
\end{abstract}

Key words Achillea ligustica; phenolic content; antioxidant; $\alpha$-amylase

The genus Achillea (Asteraceae) is represented by 26 species in Italy of which nine are endemic. ${ }^{1}$ Several Achillea species are used for their pharmaceutical, cosmetic, and fragrance properties. The extracts exhibit pharmacologic activities such as antiinflammatory, analgesic, and antipyretic properties. ${ }^{2)}$ Achillea ligustica AlL., a member of the Achillea nobilis group, has been used as medicine mainly for the treatment of gastrointestinal disorders ${ }^{3)}$ and have been previously examined for flavonoids, ${ }^{4)}$ sesquiterpene lactones ${ }^{5)}$ and essential oils. ${ }^{6}$ It has long been recognized that naturally occurring substances in higher plants have antioxidant activity, particularly flavonoids. Recently, there has been growing interest in oxygen-containing free radicals in biologic systems and their implied roles as causative agents in the etiology of a variety of chronic disorders.

Diabetes is a major risk factor for premature atherosclerosis, and oxidative stress plays an important role since diabetic monocytes produce increased superoxide anion $\left(\mathrm{O}_{2}^{-}\right){ }^{7)} \mathrm{Re}$ cent advances in understanding of the activity of $\alpha$-amylase and $\alpha$-glucosidase have led to the development of new pharmacologic agents. Amylase inhibition has gastrointestinal and metabolic effects that may aid not only in the treatment of diabetes but also of obesity. ${ }^{8,9)}$ Accordingly, attention is being focused on the protective biochemical functions of naturally occurring antioxidants and inhibitors of $\alpha$-amylase in the cells of organisms containing them. ${ }^{10,11)}$ To the best of our knowledge, there are no reports on the in vitro antioxidant and $\alpha$-amylase inhibitory activities of A. ligustica in the literature. In the present study, we used two different in vitro assays, 2,2-diphenyl-1-picrylhydrazyl (DPPH) test and lipid peroxidation of liposomes assay, to evaluate the antioxidant activity and an assay to evaluate $\alpha$-amylase inhibition of different extracts from A. ligustica.

\section{MATERIALS AND METHODS}

Chemicals Thiobarbituric acid (TBA), phosphate buffered saline (PBS), bovine brain extract, $\mathrm{FeCl}_{3}$, ascorbic acid, butylated hydroxytoluene (BHT), propyl gallate, potato starch, sodium phosphate buffer, sodium chloride, $\alpha$-amylase, sodium potassium tartrate and 3,5-dinitrosalicylic acid were obtained from Sigma-Aldrich S.p.a. (Milan, Italy). Methanol, ethanol, ethyl acetate, petroleum ether, diethyl ether, $\mathrm{H}_{2} \mathrm{SO}_{4}$, chloroform, $\mathrm{HCl}, \mathrm{KOH}, I$-butanol, silica gel $70-230$ mesh, and thin-layer chromatography (TLC) plates were obtained from VWR International s.r.l. (Milan, Italy).

Plant Materials The flowered parts of Achillea ligustica used in this study were collected (July 2003) in Calabria (Italy) and authenticated by Prof. Dimitar Uzunov, Botany Department, University of Calabria (Italy). A voucher specimen was deposited in the Botany Department Herbarium at the University of Calabria (CLU).

Preparation of the Extracts The air-dried and ground sample $(382 \mathrm{~g})$ was extracted with $\mathrm{MeOH}$ through maceration $(48 \mathrm{~h} \times 3$ times). The resulting extract was dried under reduced pressure to give $39.96 \mathrm{~g}$. Total phenols and lipophilic fraction were determined from methanolic extract. Total phenols were estimated using the method described by Karaseva et al. ${ }^{12)}$ Five grams of the methanolic extract was suspended in water $(260 \mathrm{ml})$, acidified with conc. $\mathrm{HCl}(20 \mathrm{ml})$ and extracted with $I$-butanol. The extract was treated with aqueous $\mathrm{KOH}(32 \mathrm{~g}, 400 \mathrm{ml})$. The alkaline solution was acidified with $\mathrm{HCl}(20 \mathrm{ml})$ until the $\mathrm{pH}$ became 2 and extracted with $I$-butanol. The $I$-butanol extract was washed with water and concentrated until dry. A total of $2.164 \mathrm{~g}$ of phenolic compounds was obtained $(17.295 \mathrm{~g}$ in the total methanolic extract; $4.525 \%$ in comparison to the weight of the plant).

In order to isolate the lipophilic fraction, $30 \mathrm{~g}$ of the methanolic extract was suspended in a methanol/water $(9: 1)$ mixture and extracted with $n$-hexane to give $4.604 \mathrm{~g}(6.132 \mathrm{~g}$ in the total methanolic extract; $1.604 \%$ in comparison to the weight of the plant).

GC-MS Analysis The lipophilic fraction analysis was performed using a Hewlett-Packard (HP) gas-chromatograph, model 5890, equipped with a mass spectrometer, model 5972 series II, and controlled by HP software equipped with a capillary column $30 \mathrm{~m} \times 0.25 \mathrm{~mm}$, staticphase SE30, using programmed temperature from 60 to 280 
${ }^{\circ} \mathrm{C}$ (rate $16^{\circ} / \mathrm{min}$ ); the detector and the injector were set to a temperature of $280^{\circ} \mathrm{C}$ and $250^{\circ} \mathrm{C}$, respectively (split vent flow $\left.1 \mathrm{ml} \mathrm{min}^{-1}\right)$. Compound identification was verified based on the relative retention time and mass spectra with those of Wiley 138 library data of the GC-MS system (HP). The results were also confirmed by the comparison of the compound elution order with their relative retention indices in non-polar phases reported in the literature. ${ }^{13)}$

DPPH Assay This experimental procedure was adapted from Wang et al. ${ }^{14)}$ In an ethanol solution of DPPH radical (final concentration $1.0 \times 10^{-4} \mathrm{M}$ ), test extracts were added, and their concentrations were $10,20,50$, and $100 \mu \mathrm{g} / \mathrm{ml}$. The reaction mixtures were shaken vigorously and then kept in the dark for $30 \mathrm{~min}$. The absorbance of the resulting solutions was measured in $1 \mathrm{~cm}$ cuvettes using a Perkin Elmer Lambda $40 \mathrm{UV} / \mathrm{VIS}$ spectrophotometer at $517 \mathrm{~nm}$ against a blank, in which DPPH was absent. All tests were run in triplicate and averaged. Ascorbic acid was used as a positive control.

Lipid Peroxidation of Liposomes Assay The in vitro antioxidant activity tests were carried out using the TBA test. $^{15)}$ The TBA reaction is based on the fact that peroxidation of most membrane systems leads to the formation of small amounts of free malonaldehyde (MDA). MDA reacts with TBA to yield a coloured product, which in an acid environment absorbs light at $532 \mathrm{~nm}$ and is readily extractable into organic solvents. The intensity of colour is a measure of the MDA concentration. Absorbance at $532 \mathrm{~nm}$ was determined on a Perkin Elmer Lambda 40 UV/VIS spectrophotometer. The incorporation of any antioxidant compound in the lipid peroxidation assay reaction mixture will lead to a reduction in the extent of peroxidation. The methanolic extract and phenolic and $n$-hexane fractions of $A$. ligustica were tested for their antioxidant activity against liposomes that were prepared from bovine brain extract in PBS $(5 \mathrm{mg} / \mathrm{ml})$. Peroxidation was started by adding $\mathrm{FeCl}_{3}(1 \mathrm{~mm})$ and ascorbic acid $(1 \mathrm{~mm})$, followed by incubation at $37^{\circ} \mathrm{C}$ for $20 \mathrm{~min}$. Ascorbic acid is a well-known antioxidant but it also has prooxidant properties in the presence of certain transition metal ions, such as $\mathrm{Fe}$ or $\mathrm{Cu}$. BHT in ethanol was added to prevent lipid peroxidation during the TBA test itself. Propyl gallate $(0.1 \mathrm{mM})$ was used as a positive control. $\left.{ }^{16}\right)$

$\boldsymbol{\alpha}$-Amylase Inhibition Assay It is widely accepted that the most challenging goal in the management of patients with diabetes is to achieve blood glucose levels as close to normal as possible. ${ }^{17)} \alpha$-Amylases, endoglucanases that the catalyze hydrolysis of the internal $\alpha$-1,4-glucosidic linkage in starch and other related polysaccharides, have also been targets for the suppression of postprandial hyperglycemia. We investigated extracts from A. ligustica All. To determine the inhibitory effects on $\alpha$-amylase (EC 3.2.1.1). The bioassay method was adopted and modified from SigmaAldrich. ${ }^{18)}$ A starch solution $(0.5 \% \mathrm{w} / \mathrm{v})$ was obtained by stirring $0.125 \mathrm{~g}$ of potato starch (Sigma) in $25 \mathrm{ml}$ of $20 \mathrm{~mm}$ sodium phosphate buffer $20 \mathrm{~mm}$ with sodium chloride $6.7 \mathrm{~mm}, \mathrm{pH} 6.9$ at $65^{\circ} \mathrm{C}$ for $15 \mathrm{~min}$. The enzyme solution was prepared by mixing $0.0253 \mathrm{~g}$ of $\alpha$-amylases in $100 \mathrm{ml}$ of cold distilled water. A. ligustica All. extracts were dissolved in buffer to give final concentrations from $1 \mathrm{mg} / \mathrm{ml}$ to $125 \mu \mathrm{g} / \mathrm{ml}$. The colorimetric reagent was prepared by mixing a sodium potassium tartrate solution ( $12.0 \mathrm{~g}$ of sodium potas- sium tartrate, tetrahydrate in $8.0 \mathrm{ml}$ of $\mathrm{NaOH} 2 \mathrm{M}$ ) and 3,5dinitrosalicylic acid solution $96 \mathrm{~mm}$. Both control and plant extracts were added with starch solution and left to react with $\alpha$-amylase solution under alkaline conditions at $25^{\circ} \mathrm{C}$. The reaction was measured over $3 \mathrm{~min}$. The generation of maltose was quantified by the reduction of 3,5-dinitrosalicylic acid to 3-amino-5-nitrosalicylic acid. This reaction (corresponding to the color change from orange-yellow to red) is detectable at $540 \mathrm{~nm}$. In the presence of $\alpha$-amylases inhibitors, maltose should be reduced and the absorbance value decreased. Preliminary experiments established that the optimal condition are: starch, $0.25 \mathrm{w} / \mathrm{v} \%$; $\alpha$-amylases $1 \mathrm{unit} / \mathrm{ml}$; and inhibitor concentration, $/ \mathrm{ml}$. The $\alpha$-amylases inhibition was expressed as a percentage of inhibition and calculated from the equations:

$$
\begin{aligned}
& \% \text { reaction }=\frac{[\text { maltose }] \text { test }}{[\text { maltose }] \text { control }} \times 100 \\
& \% \text { inhibition }=100-\% \text { reaction } \pm \text { S.D. }
\end{aligned}
$$

Acarbose was used as a positive control.

Statistical Analysis Data were expressed as means S.D. Statistical analysis was performed by using Student's $t$ test. Differences were considered significant at $p \leq 0.05$. The $50 \%$ inhibitory concentration $\left(\mathrm{IC}_{50}\right)$ was calculated from the Prism dose-response curve (statistical program) obtained by plotting the percentage of inhibition versus the concentrations.

\section{RESULTS AND DISCUSSION}

The methanolic extract yield and total phenol and non polar content of the flowered parts of A. ligustica are shown in Table 1 . The high yield of phenolic content $(4.525 \%)$ is of particular of interest. GC-MS analysis of the non polar fraction resulted in the identification of 43 constituents $(79.575 \%$ of the total fraction). The triterpene moretenol was the major constituent $(17 \%)$, followed by stigmast- 6 -en- $3 \beta$-ol, veridiflorol and $\beta$-amyrin $(7 \%, 5 \%, 4 \%$, respectively) (Table 2$)$. The antioxidant activities of the different extracts of A. ligustica were carried out using two different in vitro assays (DPPH and lipid peroxidation of liposomes assays). The effects of antioxidants on DPPH radical scavenging is thought to be due to their hydrogen donating ability. The scavenging effects of plant extracts on DPPH were examined at four different concentrations $(10,20,50,100 \mu \mathrm{g} / \mathrm{ml})$. As shown in Table 3 and Fig. 1, both the phenolic fraction and methanolic extract showed high activity $\left(\mathrm{IC}_{50}\right.$ values of $22 \mu \mathrm{g} / \mathrm{ml}$ and $50 \mu \mathrm{g} / \mathrm{ml}$ respectively). Different results were obtained on the lipid peroxidation of liposomes. As shown in Fig. 2 the phenolic extract showed greater antioxidative potency than the methanolic extract $\left(\mathrm{IC}_{50}\right.$ values of $27 \mu \mathrm{g} / \mathrm{ml}$ and $416 \mu \mathrm{g} / \mathrm{ml}$, respectively). The assay for $\alpha$-amylase inhibition showed that

Table 1. Content of Achillea ligustica Extracts and Yield \% in Comparison to the Weight of the Plant

\begin{tabular}{lrr}
\hline \hline Extract & Weight $(\mathrm{g})$ & Yield (\%) \\
\hline MeOH & 39.960 & 10.454 \\
$n$-Hexane & 6.132 & 1.604 \\
Phenolic & 17.295 & 4.525 \\
\hline
\end{tabular}


Table 2. Chemical Composition of $n$-Hexane Fraction from Achillea ligustica.

\begin{tabular}{|c|c|c|}
\hline Compound $^{a)}$ & $t_{\mathrm{R}}^{b)}$ & Composition (\%) \\
\hline Thujene & 6.160 & Tr. \\
\hline Sabinene & 6.966 & Tr. \\
\hline Linalool & 8.915 & 2.925 \\
\hline$\alpha$-Thujone & 9.246 & 0.282 \\
\hline t-Pinocarveol & 9.612 & 0.311 \\
\hline e-Borneol & 9.989 & 0.962 \\
\hline Lynalyl propinate & 10.292 & 2.541 \\
\hline Myrtenol & 10.384 & Tr. \\
\hline c-Jasmone & 12.870 & Tr. \\
\hline t-Caryophyllene & 13.218 & Tr. \\
\hline$\beta$-Farnesene & 13.401 & Tr. \\
\hline Alloaromadendrene & 13.699 & 0.463 \\
\hline$\delta$-Cadinene & 14.264 & 0.263 \\
\hline Nerolidol & 14.550 & 0.687 \\
\hline (-)-Spathulenol & 14.927 & 0.427 \\
\hline Veridiflorol & 15.099 & 5.078 \\
\hline Farnesol & 15.247 & 0.503 \\
\hline$\gamma$-Gurjunene & 15.699 & 2.149 \\
\hline Neophytadiene & 17.082 & 0.751 \\
\hline Hexadecanoic acid methyl ester & 17.802 & 0.836 \\
\hline Hexadecanoic acid & 17.134 & 3.721 \\
\hline Octadecanal & 18.164 & Tr. \\
\hline 1-Octadecene & 19.094 & 1.075 \\
\hline 9,12-Octadecadienoic acid, methyl ester & 19.220 & 0.818 \\
\hline Octadecanal & 20.163 & 0.555 \\
\hline Tricosane & 20.688 & 0.595 \\
\hline 1-Octadecanethiol & 21.483 & 0.407 \\
\hline Tetradecanal & 21.831 & 0.392 \\
\hline Nonadecene & 22.397 & 5.342 \\
\hline Octadecane & 23.163 & Tr. \\
\hline Cyclohexdecane & 23.426 & Tr. \\
\hline Eicosane & 24.661 & 4.841 \\
\hline Eicosane & 25.123 & Tr. \\
\hline Nonadecane & 25.735 & Tr. \\
\hline Hexadecane, 1-(ethenyloxy) & 26.135 & Tr. \\
\hline Cyclotetracosane & 27.981 & 5.977 \\
\hline 9-Tricosene & 32.999 & Tr. \\
\hline Ergost-5-en-3 $\beta$-ol & 38.234 & 1.657 \\
\hline Stigmasta-5,22-dien-3-ol & 39.435 & 3.670 \\
\hline Stigmast-6-en-3 $\beta$-ol & 42.052 & 7.524 \\
\hline$\beta$-Amyrin & 43.750 & 4.470 \\
\hline Viminalol & 46.024 & 3.125 \\
\hline Moretenol & 51.820 & 17.228 \\
\hline Others not identified (18) & & 20.425 \\
\hline
\end{tabular}

a) Compounds listed in order of elution from SE30 MS column. b) Retention time (as minutes). Tr.: Trace $(<0.1 \%)$.

Table 3. $\mathrm{IC}_{50}$ Values of Radical Scavenging on 2,2-Diphenyl-1-picrylhydrazyl and Inhibition of Lipid Peroxidation of Achillea ligustica Extracts \pm S.D. $(n=3)$

\begin{tabular}{lcc}
\hline \hline \multirow{2}{*}{ Extract } & \multicolumn{2}{c}{$\mathrm{IC}_{50}(\mathrm{mg} / \mathrm{ml})$} \\
\cline { 2 - 3 } & $\mathrm{DPPH}$ & Lipid peroxidation \\
\hline $\mathrm{MeOH}$ & $0.050 \pm 0.832$ & $0.416 \pm 1.021$ \\
Phenolic & $0.022 \pm 0.561$ & $0.027 \pm 0.325$ \\
$n$-Hexane & $\mathrm{NA}$ & $\mathrm{NA}$ \\
Propyl gallate & - & $0.007 \pm 0.213$ \\
Ascorbic acid & $0.002 \pm 0.161$ & - \\
\hline
\end{tabular}

\section{NA: no activity.}

the methanolic extract possess $28.18 \%$ of inhibition at a concentration of $1 \mathrm{mg} / \mathrm{ml}$. However $n$-hexane extracts showed $74.96 \%$ of inhibition at $250 \mu \mathrm{g} / \mathrm{ml}$ and $33.15 \%$ at $125 \mu \mathrm{g} / \mathrm{ml}$

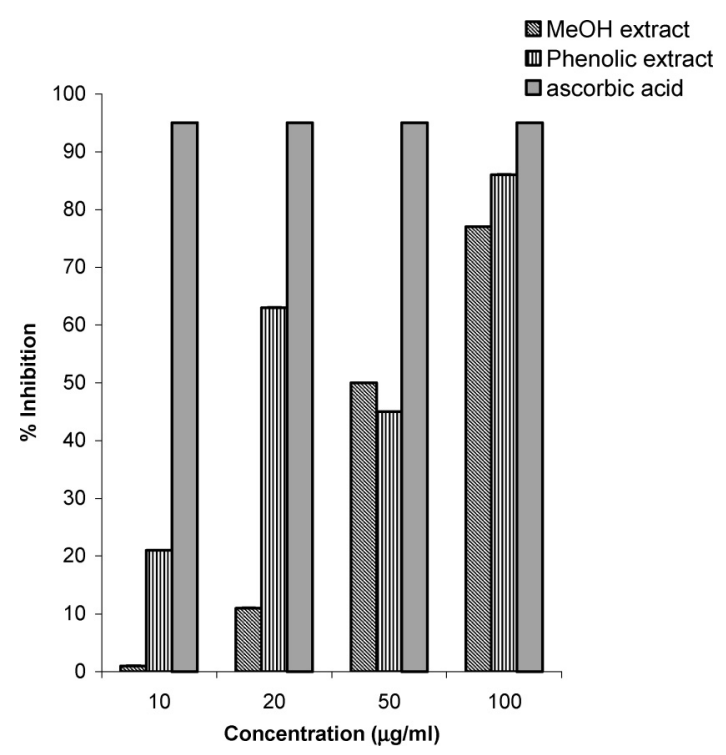

Fig. 1. Scavenging Effects of Achillea ligustica Extracts on the DPPH Free Radical

Data are means \pm standard deviation of three determinations; ascorbic acid was used as a positive control. $n$-Hexane extract showed no activity.

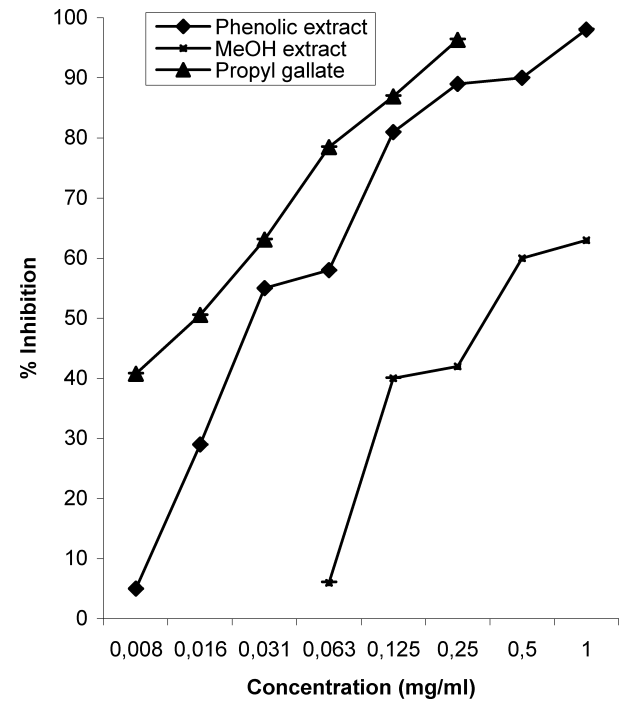

Fig. 2. \% Inhibition of Lipid Peroxidation of Achillea ligustica Extracts

Data are means \pm S.D. of three determinations; propyl gallate was used as a positive control. $n$-Hexane extract showed no activity.

Table 4. Inhibitory Activity of Various Extracts of Achillea ligustica L. against $\alpha$-Amylase \pm S.D. $(n=3)$

\begin{tabular}{ccc}
\hline \hline Extract & Concentration $(\mathrm{mg} / \mathrm{ml})$ & \% Inhibition \\
\hline \multirow{2}{*}{ MeOH } & 1 & $28.18 \pm 0.071$ \\
Phenolic & 0.5 & NA \\
& 1 & NA \\
$n$-Hexane & 0.5 & NA \\
& 1 & $89.30 \pm 0.89$ \\
& 0.5 & $85.03 \pm 0.95$ \\
Acarbose & 0.25 & $74.96 \pm 0.76$ \\
& 0.125 & $33.15 \pm 0.85$ \\
& 0.050 & $50.00 \pm 0.90$
\end{tabular}

All determinations were carried out in triplicate and averaged. The $\alpha$-amylase inhibitory activity (\%) was defined as the percent decrease in the maltose production rate over the control. Acarbose was used as positive control. NA: no activity. 
(Table 4). This activity is due probably to the triterpene moretenol which was the major constituent of the extract. The present study elucidated for the first time the biologic properties of the methanolic extract and fractions from $A$. ligustica. Particularly important are the results on the antioxidant activity of the $A$. ligustica phenolic fraction and inhibition of $\alpha$-amylase shown by $n$-hexane fraction.

Acknowledgment The authors are grateful to Prof. Carmine Lavorato, Istituto Tecnico Agrario, Cosenza, Italy for supplying the herbal sample.

\section{REFERENCES AND NOTES}

1) Pignatti S., "Flora D’Italia,” Edagricole, Bologna, Italy, 1982, p. 84.

2) Garcia M. D., Puerta R., Martìnez S., Sàenzm M. T., Phytother. Res., 11, 376-379 (1997).

3) Lodi G., "Piante Officinali Italiane," Edagricole, Bologna, Italy, 2001, p. 397.

4) Tzacou O., Couladis M., Verykokidou E., Loukis A., Biochem. Systematics Ecol., 23, 569-570 (1995).

5) Ahmed A. A., Gàti T., Taha Hussein A., Ali A. T., Tzakou O. A.,
Couladis M. A., Mabry T. J., Tòth G., Tetrahedron, 59, 3729-3735 (2003).

6) Tzakou O., Loukis A., Verykokidou E., Roussis V., J. Essential Oil Res., 7, 549-540 (1995).

7) Venugopal S. K., Devaraj S., Yang T., Jialal I., Diabetes, 51, 3049 3054 (2002).

8) Layer P., Rizza R. A., Zinsmeister A. R., Carlson G. L., DiMagno E. P., Mayoclin. Proc., 61, 442- 447 (1986).

9) Choudhary A., Marda K., Murayama R., DiMagno E. P., Gastroenterology, 111, 1313-1320 (1996).

10) Larson R. A., Phytochemistry, 27, 969-978 (1988).

11) Halliwell B., Nutr. Rev., 55, S44-S52 (1997).

12) Karaseva A. N., Karlin V. V., Mironov V. F., Konovalov A. I., Chem. Nat. Compounds, 37, 88 (2001).

13) Candan F., Unlu M., Tepe B., Daferera D., Polissiou M., Sökmen A., Akpulat A., J. Ethnopharmacol., 87, 215-220 (2003).

14) Wang M., Li J., Rangarajan M., Shao Y., La Voie E. J., Huang C.-T. H., J. Agric. Food Chem., 46, 4869-4873 (1998).

15) Fernandez J., Perez-Alvarez J., Fernandez-Lopez J., Food Chem., 59, 345-353 (1997).

16) Jacobi H., Hinrichsen M., Web D., Witte I., Toxicol. Lett., 110, 183 190 (1999).

17) Mooredian A. D., Thurman I. E., Drugs, 57, 19-29 (1999).

18) www.sigmaaldrich.com 